\title{
Comparison and Reflection on Basic Education Teaching Management between China and America from a Cross-Cultural Perspective
}

\author{
Li Luo, Fangyan Qiao \\ International Exchange and Cooperation Office, Sichuan University of Arts and Sciences, Dazhou, China \\ Email: wlxyliluo801123@163.com
}

How to cite this paper: Luo, L. and Qiao, F.Y. (2021) Comparison and Reflection on Basic Education Teaching Management between China and America from a Cross-Cultural Perspective. Open Access Library Journal, 8: e7112.

https://doi.org/10.4236/oalib.1107112

Received: December 25, 2020

Accepted: January 23, 2021

Published: January 26, 2021

Copyright $\odot 2021$ by author(s) and Open Access Library Inc.

This work is licensed under the Creative Commons Attribution International License (CC BY 4.0).

http://creativecommons.org/licenses/by/4.0/

\begin{abstract}
Education is the basis of a One-Hundred Year Strategy of a Nation, the cornerstone of nation progress, the driving force to promote national rejuvenation, and the inevitable choice to improve the quality of our citizens. Basic education is the foundation of the whole education management system. Only by doing basic education well can citizens get long-term development in their future life. Basic education management is very rich in content; this article compares the differences of the basic education teaching management between China and America from the basic education management system, teaching management and the teacher-student relationship management, hoping to help our country's basic education teaching management by learning from each other and facing up to the inadequacy and promote the healthy growth of Chinese students.
\end{abstract}

\section{Subject Areas \\ Education}

\section{Keywords}

Cross-Cultural Perspective, Basic Education in China and the United States, Teaching Management, Comparison, Reflection

\section{Introduction}

With economic globalization and social diversification, educational exchanges among countries around the world have become increasingly frequent. A large number of international conferences, exchanges of scholars and overseas study visits have promoted the development of global education. However, influenced 
by national culture, value orientation, national policy and other factors, the education concept in various countries in the world is extremely complex, resulting in different education management systems. From the perspective of cultural differences, it can be found that there're many differences in the teaching management, management system and teacher-student management between China and the United States. We should face up to the problems existing in the basic education management of our country, learn from the United States the excellent experience and offset our shortcomings, so as to make a sound development of our basic education and cultivate more talents needed by the society.

\section{Compare the Basic Education Management Systems of China and the United States from a Cross-Cultural Perspective}

As is known to all, the basic education management system of any country in the world will have a profound impact on the national education of that country. In other words, educational management system determines national teaching effect. The basic education management system of China and the United States are related with the cultures of the two countries. Our country advocates the concept of educational democracy while the United States originated from colonial culture and city-state management, and divide-and-rule is the characteristic of the basic education of the United States.

The basic education system in the United States is public-oriented with a combination of public schools and private schools. The United States has achieved twelve-year compulsory education, but still supports and encourages the development of private schools. Public schools account for about $70 \%$ in the United States and private schools account for about 30\% [1]. The basic education management system of the United States is still dominated by local government. For a long time, the federal government has lacked the direct management power over education in all parts of the United States. There is no minister-level education administration, there's only General Administration of Education, which focuses on service but lacks administrative power. With the development of the society, the United States separated the General Administration of Education in 1979 and established the Federal Ministry of Education Administration to manage the education policies and education funds throughout the United States, which showed that the education management system in the United States tended to be centralized gradually. However, the United States Education Department Organization Act clearly stipulates: "The authority and tasks related to education shall continue to be undertaken by institutions established by state and local school districts." Combined with the education regulations of the United States, it can be seen that the administrative authority of basic education in the United States is mainly concentrated in the state governments, but many state governments further devolve the administrative authority of education to the local governments for specific management of basic educa- 
tion. The subjects of education policy in the United States are diverse [2].

The administrative authority of basic education in China is mainly concentrated on the country. Under the guidance of the country, local governments at all levels are specifically responsible for the management work. Public and private schools also exist in our country. But the way of management and the systems are different. China's Ministry of Education is in charge of basic education laws and regulations, policies, guidelines, development plans, long-term goals and other work, determining the basic length of schooling, setting education goals, leading education reform, guiding the allocation of education funds, supervising and guiding the educational work of local governments at all levels. The provincial education authorities shall direct the specific work and basic education plans of the region, and evaluate the results of the regional basic education work; set special funds for education to provide financial support to lower-level governments. The county and municipal local governments mainly organize specific educational work, including fund management, teaching staff management and education management.

In practical research, it is necessary to focus on China's education tradition, possess cultural consciousness according to China's reality, and avoid indulging in pure theory learning [3]. The most obvious feature of American education management system is that the state government and the school have high autonomy and can adjust the education goals, teaching contents and education evaluation mechanism according to their own actual situation, which follows the principle of adjusting measures to local conditions. It can better benefit the local needs and students' learning needs to some extent, which promotes students' teaching adaptability. China should learn from the United States, change the traditional centralized management mechanism, gradually decentralize part of the management power, and formulate appropriate measures according to the specific conditions of each region to promote the healthy development of China's education management mechanism.

\section{Compare the Basic Education Teaching Management in China and the United States from a Cross-Cultural Perspective}

Teaching management is an important part of basic education management, which is not only related to the operation and management effect of schools, but also related to the future development of students, which plays an important part in the education management system. There are many contents in teaching management, including curriculum management, class management, teaching evaluation management and so on. The culture of China and the United States is closely related to the teaching management mechanism of the two countries. American culture attaches great importance to individuality. Their class management, curriculum management and teaching evaluation management aim to develop students' individual talent, while China has paid more attention to the general situation since ancient times. China's class management, curriculum 
management and teaching evaluation management aim to improve the quality of the people.

The main characteristic of American teaching management is the small-class model, which is based on modern educational research. Related studies in the US from some reviews of basic education research in the United States have shown that holding class with 25 to 34 students keeps most students' academic performance intact. Therefore, elementary education in the United States is mainly based on small class management. At the same time, the American teaching pays more attention to inspiration and uses heuristic teaching to inspire students' thinking. Basically, American teachers seldom pay as much attention to academic achievements as Chinese teachers do. Instead, they take students' learning level, psychological state, knowledge and experience into comprehensive consideration, and use topics they are interested in or close to their lives to inspire students' thinking and guide students to discuss and solve problems actively. In the teaching process, students are in the dominant position and teachers are in the enlightening position. In addition, teaching evaluation methods in the United States are more diversified and pay more attention to problem diagnosis, as well as mutual evaluation between teachers and students.

The most obvious feature of China's basic education teaching management is class-based teaching system. Influenced by China's economic development, infrastructure, faculty and other factors, except for some private schools in developed areas in central and eastern China, all are large-class management. The number of students in a class is basically about 50 , even more than 60 . Large class management is the key point of our current school management system. At the same time, with the education reform and the implementation of new curriculum standards, China's basic education has undergone a major change in the way of teaching. Many teachers have tried new teaching methods guided by the "student-centered concept", and some achievements have been made. However, most of the primary and secondary schools, especially primary and secondary schools in rural areas still adopt the force-feeding teaching method, impart knowledge to students mechanically, repeat knowledge by using the method of lecture, analysis method and inductive method, pay attention to student test scores very much and few of them care if the students understand the knowledge and use the knowledge flexibly. In the teaching process, there is very little interaction between teachers and students, and the limited interaction between teachers and students is mostly limited to teachers' asking questions and students' answering questions, which neither inspires students' creative thinking nor stimulates students' self-learning awareness, resulting in the problems with high marks and low abilities. In addition, in the process of teaching evaluation, the teaching evaluation of basic education in China is mainly based on achievements and dominated by teachers. The teaching evaluation means are relatively simple, and the teaching evaluation subject is more fixed, lacking flexibility and vitality.

In the basic education management, different teaching management modes 
cultivate students with different specialties. From the perspective of education results, Chinese students have a solid foundation of knowledge but lack creativity, while American students are more creative and imaginative. When American children can develop according to their own choices and interests. The American education system places great emphasis on the development of children's comprehensive abilities, including the ability of independent thinking, expression, research, organization, leadership, and teamwork; Based on the teaching management mechanism in the United States, combined with the teaching management mechanism in China, and according to the requirements of the new curriculum standards for the teaching management mechanism in China, it is necessary to constantly innovate the teaching management means and improve the teaching management effect. In terms of class management, it is necessary to provide abundant funds for basic education, establish and improve infrastructure, continuously increase the number of teachers, and gradually establish a small-class teaching system, so as to improve the class management mechanism in China. In terms of teaching means, although traditional teaching means can improve students' test scores, teachers should also see the defects of traditional teaching means, constantly try new teaching methods, focus on cultivating students' innovation consciousness, enhance their operation ability and cultivate excellent compound talents. In terms of teaching evaluation, it is necessary to change the performance-based teaching evaluation method, do our best to affirm students, praise students, motivate students, protect and respect students' fantastic ideas, cultivate students' desire to create and thirst for knowledge, and promote students' learning confidence.

\section{Compare the Teacher-Student Relationship between Basic Education in China and the United States from the Cross-Cultural Perspective}

Teacher-student relationship management is a part of basic education management. Only by establishing an equal and harmonious teacher-student relationship can students truly identify with teachers psychologically, actively learn teachers' words and deeds, be closer to teachers, and be subtly influenced by teachers. In practical teaching, the teacher-student relationship plays a great role, which is not only related to the realization of teaching objectives, but also related to the harmony of interpersonal relationship, teaching relationship and campus relationship, which is the most critical relationship in teaching management. The relationship between teachers and students is not only an important part of campus management, but also closely related to social activities, which is the product of national history and culture. Influenced by national culture, people's different cognition of teacher-student relationship reflects the education values dominated by different social culture.

In the American basic education, a basic education concept is student-centered, which opposes teachers to lead students with an authoritative role and focuses on creating equal relations [4]. This concept of teacher-student relationship 
conforms with the logic of education. Excessive authority of teachers may have a negative impact on students' personality and talent, self-behavior, self-confidence and other aspects, which is not good for the cultivation of students' creative thinking and affects their future development. Under the influence of national consciousness, American educationalists strongly advocate the equal teacher-student relationship based on democracy, which is more free and fully demonstrates the equality of teachers and students. In classroom teaching, if there is disagreement between teachers and students, teachers and students will have a debate, during which teachers' professional development and students' ability will be achieved to promote win-win cooperation between teachers and students. Outside of the classroom teaching, the teacher is a friend of the students, they care about the student's inner emotion world, and often talk with the students about their dream and share life experience, strengthen understanding between the teachers and students in the harmonious relationship and promote mutual trust, finally making the students willing to talk to the teacher, daring to doubt, thus developing the students' comprehensive quality. The main characteristic of the teacher-student relationship in the United States is the equal relationship like friends. Meanwhile, for a long time, the social status of teachers in the United States is not high, and most of the teachers in the United States are women. It is difficult for women to achieve the same equal social status as men in the United States. The image of teachers is closely related to female, which finally causes problems in the social reputation of teachers in the United States [5]. Teachers' low social status, to some extent, leads to students' less yearning to be teachers, which affects the construction of teacher-student relationship.

In China, Confucianism has long occupied the dominant position, under the influence of Confucianism, respect for teachers is China's unique culture. China has Teachers' Day, while the United States does not have a holiday for teachers. From this, we can see the different status of teachers in China and the United States. However, the teacher-student relationship, which is dominated by teachers, also has a bad influence on our basic education. In the teacher-student relationship in China, most teachers play a leading role and focus on students' examination results, lacking communication with students. In this case, there's distance between teachers and students, with teachers in a superior position and in charge of the whole teaching activity without much communication with students, resulting in passive learning and failing to establish a democratic and equal relationship between teachers and students. At the same time, the communication between teachers and students in China is basically centered on the theme of "scores", and little attention is paid to students' emotional world and life needs, as well as students' real life. There's distance between teachers and students, our students are alienating their teachers, and some even guard against them. Few of them are willing to have in-depth communication with teachers or express their real thoughts, so teachers can't understand students from their perspective, ultimately affecting the teaching effect.

It is worth advocating teachers' high social status in China, which is helpful to 
stimulate teachers' working enthusiasm and sacrifice spirit. However, based on the cultural differences between China and the United States, China needs to continuously improve the relationship between teachers and students on the basis of carrying forward the traditional culture of "honouring teachers and respecting the teaching". To change the communication way focused on the scores, teachers should become a friend of students by communicating with them about the learning problems, life problems, life confusion, life experience, and so on. At the same time, teachers need to change the teaching attitude, besides focus on students' academic achievement, teachers should take the initiative to interact with students after class, become a trustworthy friend of the students, so that students dare to talk to teachers and the teachers know the real thought of students, building equal and harmonious relationship between teachers and students. Of course, in this process, teachers need to face up to the shortcomings of students. In basic education stage, students will inevitably have a variety of problems, such as learning problems, life issues, or behavioral problems, teachers need to view students' problems rationally, be tolerant of students' mistakes, making students feel the teachers' care, so as to build a more harmonious relationship between teachers and students.

\section{Conclusion}

In short, China's social progress has posed a new challenge to basic education: how to put the "people-oriented" educational concept into practice, to promote the research of discipline core literacy and learning segment education core literacy. Only by keeping up with the trend of the times and taking the initiative to innovate and achieve a comprehensive understanding, can we promote the healthy development of children. From a cross-cultural perspective, the basic education management methods of China and the United States have their own advantages and disadvantages, which need to be paid attention to by front-line teachers and educators. We need to change education idea, and strengthen curriculum reform, create a good environment for the development of teachers, pay attention to the development of students' nature and deepen the implementation of quality-oriented education, increase investment in basic education, cultivate compound talents with creativity, imagination and practical ability, thus to better implement the strategy of developing the country by relying on science and education in our country, make long-term healthy development of basic education in our country, provide energy for our country's socialist modernization construction and provide impetus for the vigorous development of China's educational undertakings.

\section{Conflicts of Interest}

The authors declare no conflicts of interest regarding the publication of this paper.

\section{References}

[1] Wang, Y. (2007) Comparative Study on the System, Teaching and Evaluation Me- 
thods of Basic Education in China and the United States. Journal of Inner Mongolia Normal University (Education Science Edition), 4, 43-45.

[2] Yao, Z. (2010) Comparative Research on Curriculum Policies of Basic Education between China and the United States. Forum on Education Science, 7, 14-16.

[3] Yan, C. (2012) Where Should China's Educational Research Go. Research on Educational Development, 9, 42-46.

[4] Qiang, H. (2005) Research on Basic Education in China, America, Canada and Britain. People's Education Press, Beijing.

[5] Laghman, E.C. (2006) An Elusive Science: The History of Troubling Educational Research. Education and Science Press, Beijing. 